
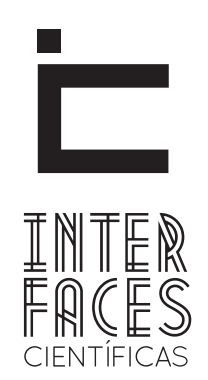

EDUCAÇÃO

ISSN IMPRESSO 2316-333X

E-ISSN 2316-3828

DOI-10.17564/2316-3828.2017v6n1p201-212

\title{
RECURSOS CRIATIVOS, MÍDIA LOCATIVA E ARTE URBANA: EXPERIENCIANDO O LUGAR DURANTE O PROCESSO DE APRENDIZAGEM ${ }^{1}$ \\ CREATIVE RESOURCES, LOCATIVE MEDIA AND URBAN ART: EXPERIIENCING THE PLACE DURING LEARNING PROCESS RECURSOS CREATIVOS, MEDIOS DE COMUNICACIÓN Y ARTE URBANO: EXPERIMENTANDO EL LUGAR DURANTE EL PROCESO DE APRENDIZAJE
}

\section{RESUMO}

Este trabalho realiza um estudo teórico discutindo as noções de mídia locativa, espaço, lugar e cidade para descrever um objeto de aprendizagem. Trata-se de um aplicativo para smartphone desenvolvido no âmbito do Laboratório de Estudos de Mídia e Espaço (LEME/ $\mathrm{CNPq}$ ) e no Programa de Pós-graduação em Educação, Cultura e Territórios Semiáridos, da Universidade do Estado da Bahia com foco de aumentar a visibilidade das informações culturais, artríticas e turísticas da re-

\footnotetext{
1. Artigo baseado na dissertação de Mestrado defendida por Cecílio Bastos, intitulada "Cartografia Urbanográfica no Sertão do São Francisco: uma proposta infocomunicacional a favor da articulação de novos espaços de arte e educação", sob orientação de Luiz Adolfo Andrade, no Programa
}

gião do Vale do São Francisco. A partir de uma pesquisa bibliográfica, pretende-se descrever a parte deste projeto que indexou dados relativos à urbanografia do município de Juazeiro - BA. Ao final, conclui-se que o processo de aprendizagem proporcionado pelo aplicativo é devedor da criação de um lugar, com base na posição do usuário e da localização da obra de arte sobre o espaço urbano.

de Pós-Graduação em Educação, Cultura e Territórios Semiáridos (PPGESA) da Universidade do Estado da Bahia., em fevereiro de 2017. Esta pesquisa não envolveu seres humanos, portanto fica excluída a necessidade de aprovação por comitê de ética. 


\section{PALAVRAS CHAVE}

Espaço. Lugar. Aprendizagem. Midia Locativa. Comunicação.

\section{ABSTRACT}

This work conducts a theoretical study discussing the notions of locative media, space, place and city to describe a learning object. It is an application for smartphone developed in the Laboratory of Media and Space Studies (LEME / CNPq) and in the Postgraduate Program in Education, Culture and Semi-Arid Territories, of the State University of Bahia with a focus on increasing visibility of the cultural, arthritic and tourist information about the the 'Vale doSão Francisco.' Following a literature review, we intend to describe a part of this project that indexed data related

\section{RESUMEN}

Este trabajo realiza un estudio teórico discutiendo las nociones de medios locativos, espacio, lugar y ciudad para describir un objeto de aprendizaje. Se trata de una aplicación para smartphone desarrollado en el ámbito del Laboratorio de Estudios de Medios y Espacio (LEME / CNPq) y en el Programa de Postgrado en Educación, Cultura y Territorios Semiáridos, de la Universidad del Estado de Bahía con foco de aumentar la calidad Visibilidad de las informaciones culturales, artríticas y turísticas de la región del 'Vale do São Francisco'. A partir de una revisión de literatura, se pretende describir la parte de este proyecto que indexó datos relativos a la to the urbanography of Juazeiro - BA. We conclude that the learning process provided by the application is indebted to the creation of a place, based on the user's position and the location of the work of art on the urban space.

\section{KEYWORDS}

Space. Place. Learning. Locative Media. Communication. urbanografía del municipio de Juazeiro - BA. Al final, se concluye que el proceso de aprendizaje proporcionado por la aplicación es deudor de la creación de un lugar, con base en la posición del usuario y de la localización de la obra de arte sobre el espacio urbano.

\section{PALABRAS CLAVE}

Espacio. Lugar. Aprendizaje. Medios Locales. Comunicación. 


\section{INTRODUÇ̄̃̃O}

Muito se discute a respeito do papel dos smartphones e dos tablets na educação. É sintomático perceber que alguns professores simplesmente preferem impedir que alunos utilizem esses dispositivos na sala de aula, em vez de pensar alternativas para apropriações dessas ferramentas como objetos de aprendizagem (OA). Os aplicativos (Apps), por exemplo, poderiam ser utilizados como recurso para atividades nas diferentes cadeiras do ensino fundamental, médio e/ou superior, esferas nas quais os tablets estão se tornando mais disponíveis para estudantes do Vale do São Francisco (CRUZ \& NERI, 2014).

0 estudo aqui realizado busca contribuir com reflexões sobre modos de experienciar o lugar, considerando o potencial das mídias locativas e dos aplicativos com funções georeferenciadas, caracterizando um objeto de aprendizagem contextualizado com a região do Vale do São Francisco, semiárido brasileiro. Para tanto, iremos realizar uma pesquisa bibliográfica acompanhada de um relato de nossa experiência no projeto Cartografia Urbanográfica no Sertão do São Francisco (CAUS), desenvolvido no Laboratório de Estudos de Mídia e Espaço (LEME/CNPq) e no Programa de Pós-graduação em Educação, Cultura e Territórios Semiáridos, localizados no DCH-III da Universidade do Estado da Bahia, município de Juazeiro-BA.

0 CAUS se insere no âmbito de um projeto mais amplo, desenvolvido pela mesma equipe, nos mesmos laboratórios e instituição, chamado SmartChico: cartografia cultural do Sertão do São Francisco. O SmartChico tem como objetivo indexar aspectos urbanográficos, pontos turísticos e equipamentos culturais públicos dos municípios pertencentes ao chamado Território de Identidade Sertão do Francisco, a saber: Campo Alegre de Lourdes, Canudos, Casa Nova, Curaçá, Juazeiro, Pilão Arcado, Remanso, Sento Sé, Sobradinho e Uauá, todos situados no estado da Bahia. A proposta consiste em criar um aplicativo georeferenciado, que estará disponível gratuitamente nas lojas Google Play (Android) e App Store (iOS), para auxiliar a navegação do usuário nessas cidades, em meio às informações urbanográficas, turísticas e culturais. Ao mesmo tempo, pretende-se com esse projeto auxiliar na divulgação da Cultura do Sertão do São Francisco na internet e criar um objeto de aprendizagem que funcione como ferramenta nas escolas da região.

As atividades no âmbito do SmartChico, que abarcam os procedimentos feitos no projeto CAUS, podem ser divididas em três momentos. No primeiro, realizado entre março de 2015 e junho de 2017, foram indexados dados relativos a cinco cidades: Juazeiro, Curaçá, Remanso, Sobradinho e Casa Nova. Nesta fase, foram gerados três mapas usando a base de dados do Open Street Maps, compilando dados pertinentes à urbanografia ${ }^{2}$, cultura ${ }^{3}$ e turismo $0^{4}$ dos municípios citados acima. 0 segundo momento consiste no desenvolvimento do aplicativo, que usará como base os dados gerados na fase um. Os testes no app. serão feitos no segundo semestre de 2017 e o lançamento da versão beta está previsto para o início de 2018. A terceira fase, ainda sem previsão de acontecer, consistirá na catalogação dos dados encontrados nos outros cinco municípios que integram o território de identidade Sertão do São Francisco.

As fases um e dois do projeto SmartChico contaram com apoio do Departamento de Ciências Humanas III da UNEB e da Fundação de Amparo à Pesquisa do Estado da Bahia (FAPESB). A equipe de trabalho é composta por um pesquisador doutor (UNEB), três mestres (um da UNEB e dois do Instituto Federal da Bahia - IFBA) e outros três pesquisadores de iniciação científica (UNEB), além do programador terceirizado, que está desenvolvendo o aplicativo.

Considerando as dimensões previstas para este trabalho, nos limitamos à apresentar uma descrição das atividades realizadas na cidade de Juazeiro, considerando a captação e indexação das informações

2. http://caus.eco.br/geoart/ acesso em Jun. 2017

3. http://caus.eco.br/geocult/ acesso em Jun. 2017

4. http://caus.eco.br/geotur/ acesso em Jun. 2017 
pertinentes à urbanografia. Nosso objetivo aqui é mostrar que o potencial do aplicativo como objeto de aprendizagem está relacionado à criação de um lugar, produzido a partir do uso da mídia em mobilidade sobre o espaço urbano. Esse lugar funciona como mediador entre usuário, a cultura regional e a cidade, revelando uma alternativa para atividades pertinentes ao ensino no âmbito da cibercultura.

Para realizar este trabalho, iniciamos apresentando uma discussão sobre mídia locativa, lugar e ensino. Neste momento, pretendemos apresentar as bases para a compreensão de como a mídia locativa pode contribuir para a produção de lugares, a partir da posição do usuário no espaço urbano e da localização do conteúdo artístico. Em seguida, buscamos compreender como a cidade pode ser considerada a base para atividades com as mídias locativas, permitindo refletir como o lugar pode figurar como mediador em nossa experiência social, atuando na relação usuário, mídia e espaço. Por fim, apresentamos uma abordagem sobre as interfaces de aprendizagem na contemporaneidade, culminando em uma descrição da nossa experiência com o projeto da Cartografia Urbanográfica no Sertão do São Francisco.

Urbanografia é um conceito enfatizado a partir da década de 1960, que abrange um conjunto de manifestações artísticas encontradas no ambiente urbano. As intervenções foram inicialmente instauradas em abundância sob a forma de esculturas. Construídas essencialmente com materiais nobres, logo passaram a explorar outros materiais que se relacionavam melhor com uma característica mais visceral das ruas. Em consequência, linguagens híbridas passaram a ser espontaneamente reconhecidas, fortalecendo um movimento que cada vez mais cultivava uma linguagem plurissignificativa e capaz de abranger conteúdos interdisciplinares factuais, isto é, criar narrativas atuais acerca do espaço onde estavam inseridas. Justamente por apresentar uma relação muito próxima com a cidade, o trabalho de discutir questões pertinentes à urbanografia e a produção de um objeto de aprendizagem - no caso, o aplicativo - aponta para outros conceitos que se tornam consideravelmente importantes.

\section{MÍDIA LOCATIVA, ESPAÇO E LUGAR}

Discutir a noção de mídia locativa convoca, inevitavelmente, uma abordagem sobre definições de espaço e lugar. É particularmente interessante destacar que, de modo seminal, essa terminologia foi criada justamente para fins de ensino e aprendizagem. Durante workshop realizado na Letônia, em 2003, o artista Karlis Kalnis propôs o conceito de mídia locativa para se referir, nas suas explanações, às atividades realizadas com tecnologias e serviços baseados em localização ${ }^{5}$. Um meio de comunicação pode ser considerado locativo quando possui a qualidade de agregar conteúdo informacional à determinada localização. Nestes casos, via de regra, emissão e recepção devem ocorrer sempre em nível local, disponibilizando serviços de acordo com a posição do usuário. Para André Lemos (Cf.:2010, p.10), as mídias locativas produzem um fluxo comunicacional que se dá localmente, identificando a posição do usuário e propondo serviços locais. Lugar e contexto figuram como elementos essenciais, favorecendo novos usos do espaço.

$\mathrm{Na}$ gramática portuguesa, conforme observa Medeiros (2011), o adjetivo "locativo" refere-se a tudo que está relacionado ao lugar. Na linguística, temos o "caso locativo", que refere-se à "circunstância de lugar" ou "que situa em um lugar aquilo que é exposto no enunciado". Pode ser encontrado em diversos idiomas, como o alemão, o grego, o latim, o japonês e o russo. Em português, o "caso locativo" é marcado pelo uso da preposição "em", seguida ou não dos artigos "o(s) / a(s)", gerando as contrações "no(s) / na(s)", além do prono-

\footnotetext{
5. As tecnologias baseadas em localização incluem sistema de posicionamento global, etiquetas como QRCode e RFID, computadores tablets, smartphones, redes sem fio que dependem da localização de antenas e da cobertura de sinal de telefonia para operar, como 3G, 4G e Wi Fi, além do Bluetooth, que permite o envio em curta distância de mensagens de áudio, vídeo e texto. Os serviços baseados em localização, por sua vez, consistem nos mapas configurados a partir de bancos de dados (como Google Maps e Apple Mapkit) que permitem acesso e leitura rápida de informações geoespaciais, anotações urbanas (como as criadas a partir de apps como Map My Ride, Strava, Map My Run), etiquetas georreferenciadas (geotags), browsers de realidade aumentada (Junaio, Layar etc.), redes sociais que agregam informação geoespacial (Facebook, Foursquare, Twitter etc.) às mensagens de usuários (posts, comentários, check-ins, tweets etc.), dentre outros.
} 
me "onde" e das contrações "naquele(s), naquela(s)". Por isso, a noção de "mídia locativa" aponta para uma relação intrínseca do meio com o lugar.

Um lugar, segundo Michel de Certeau (1984), pode ser compreendido como produto de uma configuração instantânea de posições, na qual os elementos envolvidos são distribuídos seguindo a lei do próprio: eles se acham uns ao lado dos outros, sem que dois corpos ocupem o mesmo lugar no espaço. Para Tim Cresswell (2004), um lugar é composto basicamente de três elementos, nomeados localização, local e sentido de lugar. A localização corresponde ao ponto único no espaço ocupado pelo lugar, que é determinado por coordenadas de latitude e longitude. 0 local se relaciona à maneira pela qual um lugar "aparece" para nós, levando-se em conta a forma física, aspectos de infraestrutura e estrutura de prédios, casas, praças, parques etc. 0 sentido de lugar emana de vínculos simbólicos e emocionais associados pelas pessoas ao lugar. Estes significados podem ser temporários, individuais ou compartilhados, baseados na mediação e na representação produzidas pelas pessoas sobre o espaço, gerando os lugares. A ideia de espaço, por sua vez, aponta sempre para algo abstrato, intangível, que serve de base para posicionamento dos corpos e das coisas, onde se ancoram as relações desenvolvidas entre pessoas e objetos.

Sob esta perspectiva, o espaço urbano pode ser apropriado como suporte para ações envolvendo mídias locativas e seus usuários, emanando um sentimento subjetivo e/ou compartilhado, a partir da criação de lugares. Esses lugares podem ser concebidos como mediadores em nossa experiência cotidiana, podendo servir de recurso para a educação. A cidade, portanto, passa a figurar como base para explorações envolvendo as mídias locativas, servindo aos diferentes fins, dentre eles o ensino e a aprendizagem.

\section{AÇÕES RELACIONAIS NO ESPAÇO URBANO}

A cidade é um componente da criação humana, erguida no tempo e no espaço, que compactua movi- mentos estratégicos para o aparelhamento da vida em comum. Mas o que se chama de espaço urbano estrutura-se a partir do século XIV, na Europa Ocidental, quando as cidades transformam-se em pólos comerciais. 0 termo urbano vem do latim urbs, significando cidade em oposição ao rural, rus. 0 urbano designa um conceito mais ligado ao comportamento nas cidades. Já a palavra inglesa city vem do francês cite, que originalmente significava lugares de importância, de poder. Em muitas passagens das Ciências Sociais a cidade é tratada como um organismo vivo, construída através de formas de redes.

Compreende-se, sob a perspectiva de Lefebvre (2001), que o urbano avoluma um grande e agitado conjunto de forças tensionadas contra o paradigma vigente. Reforçando o conceito de social como equivalente à associação, coisas que estão sempre em movimento e estabelecendo conexões, o autor designa o urbano como uma forma em sincronia com as múltiplas questões de interesse e a cidade como o artefato que marca a espacialidade e a circunstância, portanto, a proeminência das afirmações de formas sociais sobre um lugar.

Ainda que os atores sociais tenham perdido muitas de suas habilidades contemplativas frente à cidade e as diretivas institucionais insistam em compactuar com o falso desenvolvimento, a urbanização se configura como uma perspicaz controvérsia. É no urbano que está contida a potência das requisições transformativas, porque é sempre uma zona densa, inacabada e indutora de qualidades; “[...] para realizá-lo, é preciso em princípio contornar ou romper os obstáculos que atualmente o tornam impossível" (LEFEBVRE, 2004, p. 28). Nessa paisagem, Lefebvre (2001) delega às resistências o poder de reconstituir tramitações que extrapolem o estabelecimento da diferença, da manifestação contrária a alienação, e destaca que "[...] o ato de habitar é uma condição revolucionária porque é capaz de se opor dialeticamente ao movimento de homogeneização do capital, mas habitar não se resume apenas a ter uma moradia, afinal, trata-se do direito à cidade no sentido político mais profundo possível" (ARAÚJO, 2012, p. 136). 
Neste sentido, o projeto CAUS pode revelar um caminho para (re)apropriação da cidade através da arte e das mídias locativas. Este procedimento é operado com base em uma "produção social de espaço" (LEFEBVRE, 2000), criada a partir de práticas espaciais, representações de espaço e espaços de representação.

Enquanto 'espaço de representação', a obra de arte é também um agente na produção do espaço, adentrando-se nas contradições e conflitos aí presentes. Tomando-se o território urbano como campo de processos sociais, a arte urbana, nesses termos, pode alinhar-se com interesses destacadamente distintos na produção da cidade. Esta abordagem da cidade como forma social ao invés de objeto físico (não como infra-estrutura externa aos 'usuários', mas produzida por eles) encara a arte urbana como um certo empenho na requalificação do seu cotidiano. (PALLAMIN, 2000, p. 46)

Fazendo uma relação entre a educação e os aspectos citados acima, não se torna inoportuna a afirmação de que a cidade comporta diversas possibilidades educadoras. "Enquanto educadora, a cidade é também educanda” (FREIRE, 1993, p. 23). A pulsação que vibra através da operabilidade civilizatória deposita na cidade qualidades, mas que, por imbricações controladas pela ordem capital, conexas e mantenedoras das dinâmicas expansionistas aportada no lucro de poucos, exigem uma percepção acurada dos indivíduos para o melhor entendimento das mensagens e pulverização dos concentrados bolsões de saber. 0 habitar como ação revolucionária, no sentido lefebvriano, mobiliza circunstâncias de uma constante e espontânea composição da aprendizagem.

Um movimento, talvez menos perturbador da formalização institucional presente no urbano, é a ascensão da cidade intencionalmente educadora. De acordo com Gadotti (2006, p. 134) "uma cidade pode ser considerada como uma cidade educadora quando, além de suas funções tradicionais - econômica, social, política e de prestação de serviços -, ela exerça uma nova função cujo objetivo é a formação para e pela cidadania”. Invariavelmente, isso implica na clarificação dos direitos, na conscientização dos deveres e na consequente "auto-governabilidade" dos grupos, condições envoltas por blindagens estanques preparadas para diluírem os resíduos colhidos pelas resistências. Mesmo as muitas experiências significativas, portanto, não estão imunes aos portões que regulam o fluxo das atividades que experimentam quebrar paradigmas e empoderar a coletividade. De toda sorte, é fundamental a constante provocação para uma reflexão sobre o sentido da experiência do espaço e do lugar. Porque "a experiência implica a capacidade de aprender a partir da própria vivência. Experienciar é aprender; significa atuar sobre o dado e criar a partir dele" (TUAN, 2013, p. 18).

Sobretudo nas últimas décadas, a educação tem ficado subordinada à doutrina neoliberal, que fabrica a agenda do ensino baseada nos rendimentos econômicos e impulsiona estatísticas pareadas com os interesses equidistantes das instituições financeiras. A corrida por uma nova mentalidade deve mirar o empoderamento sobre as possibilidades de inscrição nos espaços para que o indivíduo resgate a noção do seu protagonismo e retome o olhar para a cidade, enxergando-a como uma obra de arte.

\section{INTERFACES DE APRENDIZAGEM NA CONTEMPORANEIDADE}

Um debate frequente tem circulado sobre o universo da educação: a busca pelo entendimento do lugar da escola no século XXI. Compreende-se, em primeiro plano, que a escola não se configura como um veículo da informação, mas como um território de constituição do conhecimento. Assim, uma das funções primordiais da escola assenta na sua capacidade de colaborar com a (re)invenção da cultura, ainda que esteja inserida nela. Essa demanda transcorre pela amplitude, transparência e debate dos saberes que, com muito esforço, pode atingir uma nova conscientização dos processos cotidianos.

Percebe-se que, com muito custo das longas batalhas travadas nas diversas esferas, sobretudo con- 
tra o conservadorismo que acoberta uma espécie de neonazismo legal, as escolas públicas no Brasil têm buscado disponibilizar recursos que apoiem o respeito e a valorização das diferenças. Mas esse esforço ainda não se mostra suficiente para dilatar toda a potencialidade dos novos espaços de inscrição desta era digital, porque não basta que sejam apenas gestoras do conhecimento com os velhos exercícios de reprodução da existência. Na mesma medida, não a compete mais ser destacada como um monumento da cidade, um marco que sacramenta as "belas" e "lindas" histórias de um lugar. A presença da escola na cidade é muito mais que um aspecto material. De certo, a imponência física do prédio é hoje a menor das suas qualidades e que pouco diz respeito sobre a lógica das rupturas possíveis.

Pelo o que se forma através das colisões conceituais, a instituição escolar carece de empenho com a articulação das práticas próximas aos atores sociais, sem que esse movimento represente uma maneira de repressão em qualquer grau e negligencie as hibridizações. As significações necessitam apontar para atividades transformadoras que culminem em conhecimentos sempre inconformados, mesmo nos espaços de formação crítica.

Precisamos de uma pedagogia da cidade para nos ensinar a olhar, a descobrir a cidade, para poder aprender com ela, dela, aprender a conviver com ela. [...]. Existe uma prática da ocultação das diferenças, também decorrente do medo de ser tocado por elas, sejam as diferenças sexuais, culturais etc. [...]. Temos que aprender a nos locomover na cidade, caminhar muito por nossas ruas. [...]. Precisamos de mapas, de guias. Precisamos saber onde a gente se encontra. [...]. A cidade nos pertence e, porque nos pertence, participamos da sua construção e da sua reconstrução permanente. Precisamos conhecer os equipamentos culturais da cidade. Qualquer programa que tenta interconectar os espaços e equipamentos é fundamental, pois desconhecemos a nossa própria cidade ou subutilizamos as suas potencialidades. (GADOTTI, 2006, p. 139)

A urbanografia não se limita a subjetivação estética e inúmeras propostas de aditamentos surgem alinhadas com a produção do conhecimento, o incremento da mentalidade crítica e o desenvolvimento cultural. Revela-se de imediato como um ator peculiar na concepção das associações no coletivo que, por conseguinte, provoca outro mediador a criar diálogos com as informações acessadas e o convida a extrapolar a experiência da etapa contemplativa.

Considerando as diversas etapas do processo criativo e todas as suas ambiguidades, as intervenções urbanas brotam na paisagem com intencionalidades e problematizações que perpassam pela própria e contínua (re)constituição projetiva. As mensagens latentes das obras comumente legam uma representação do espaço decifrado pelo autor. Trata-se de um modo de existência atrelado às estratégias de proclamar, de comunicar, uma vez que sugere buscar potencializar a competência de propagar mensagens, na medida em que anseia o desdobramento de outras traduções.

É possível identificar, em projetos pontuais, que através do estímulo e mediação no campo da arte, o educador pode propiciar a eclosão de diversos sentidos nas experiências do educando. No caso da urbanografia, as inter-relações entre comunidade e cidade indiciadas nas obras provocam os receptores para que ampliem a percepção ambiental promovendo, entre outras coisas, a assimilação da linguagem visual urbana, ou seja, maximiza a identificação de aspectos do espaço como importante fonte de dados. Evidencia-se, nesse sentido, um aditivo às funções cotidianas intrínsecas à cidade.

Conjetura-se que, através da apropriação dos espaços caracterizados por manifestações artísticas visuais, estudantes poderão ser incentivados a libertar e explorar elementos da cidade. São diálogos que extrapolam os encontros temporários nas salas de aula. "A própria cidade se faz matéria de criação não apenas do artista, mas de todos que reinventam os sentidos do espaço urbano através da experiência estética compartilhada" (MENDES, 2012, p. 6). Em diversas ações difundidas, essa intermediação se mostrou como uma importante oportunidade para que jovens percebessem a cidade como um território de inscrição, clarificando um canal comunicativo e sucumbindo invisibilidades para possibilitar o fortalecimento de uma relação sensível e estética das trilhas locais. 
Uma vez que costumam enfatizar os temas que representem os conflitos cotidianos, a urbanografia projeta a existência como um objeto capaz de (re) aproximar os indivíduos da cena contextual. Além disso, com a disseminação dessas manifestações, a cidade adquire a efemeridade presente nas obras e perde sua qualidade estática. Se transforma em um organismo constantemente sujeito a mutações. Cartaxo (2009, p. 14) ratifica que "a arte nos espaços públicos lida com a recuperação das relações entre o homem e o mundo, entre o sujeito e a cidade, tendo em vista os problemas que a área urbanística vem enfrentando e que afetam tais relações".

Com a atual dinâmica da urbanografia, distinguida pela enfática capacidade de ousar na utilização de locais e materiais inusitados para representar o universo heterotópico, ratifica-se a necessidade de incorporar na educação, sobretudo no planejamento das aulas de Artes, atividades que apontem para essas manifestações criativas, no sentido de fazer cada discente enxergar, analisar e interpretar a arte como parte existencial da cidade. Reconhecida como fonte de conhecimento cultural, a urbanografia pode, ainda, auxiliar o educando a conectar a realidade próxima a totalidades mais abrangentes.

A obrigatoriedade do componente "Artes" no ensino fundamental intercede no exercício pedagógico transformando o ultrapassado ensino baseado na memorização e repetição em uma educação voltada para a formação do indivíduo apto a subjetivar as complexidades do mundo. Frente a isso, a urbanografia surge como um tema gerador a partir da necessidade que o educador tem em explorar outras táticas que inovem a prática pedagógica. Esse eixo conceitual se posiciona muito próximo das considerações de Paulo Freire (2009) sobre o ensino com o uso de temas geradores.

No momento que o próprio conteúdo abordado perfilha o educando como indivíduo fundamental, se forma uma melhor compreensão sobre a necessidade do ato de aprender. Isso faz ampliar as questões de interesse em escala constante. Possivelmente, uma inserção ampla da arte urbana como conteúdo das aulas proporcionaria um ensino e aprendizagem con- textualizada, estimulando atores a promoverem ações desafiadoras atreladas à área do conhecimento. Além disso, considerando o panorama revelado em outras pesquisas, poderia promover um interesse entre os diferentes discursos. Uma chance para fazer vibrar o fluxo de informações e reduzir as equações que indicam para o eixo crescente da sintomática evasão escolar.

Uma explanação sobre a arte não apenas gera uma interdisciplinaridade de conhecimentos aplicados na vida em comunidade, mas o exercício da capacidade perceptiva e sensitiva. Implica em restabelecer o educando como indivíduo ativo no processo pedagógico, instigando formas de expressar perspectivas de sua realidade, expor a intelectualidade, expandir a atividade criativa e desenvolver a multiculturalidade. Além disso, o educando é levado a reconhecer e valorizar algo cada vez mais presente em nosso território: a participação ativa nos contextos decisivos de organização política e comunitária. Tais recambiamentos, potencializados pela interculturalidade praticada, poderia suscitar nos indivíduos o mútuo reconhecimento de agências transformadoras, já que

[...] a percepção de si mesmo dentro do agir no cotidiano, é um aspecto relevante que distingue a criatividade humana, movida pelas necessidades concretas sempre novas. O potencial criador do homem e da mulher surge na história como um fator de realização e constante transformação. Ele afeta o mundo físico, a própria condição humana e os contextos sócio-culturais existentes em cada lugar. Daí a importância de fomentarmos, enquanto movimento de discussão de uma educação para convivência, as possibilidades criadoras e criativas que busquem capacidades de deixarmos enraizar no outro e o outro em nós, sem destruí-lo ou destruir-nos e, principalmente, a capacidade de desenraizar e reenraizar sempre que preciso for. (PEREIRA, 2006, p. 187)

Inserida na vida dos indivíduos, permeando os imaginários, as manifestações visuais urbanas podem contribuir para o conhecimento e o envolvimento da comunidade discente com vozes próximas e/ou gritos distantes. Vale ressaltar que toda essa proposição investigativa compactua com uma escola que garanta aos seus estudantes o estabelecimento de subjetivi- 
dades sensíveis à lógica de um conceito de progresso mais consciente. Vincula-se ao reconhecimento dos processos educativos que rompem com os modelos estereotipados, que abandonam as práticas sensacionalistas e que repudiam o reducionismo cultural. Incumbe-se na busca por competências que regem o aprimoramento dos mecanismos aderentes a procedimentos viabilizadores de uma recolocação da expertise criativa a partir da convivência com o espaço contextual.

\section{DESCREVENDO O PROJETO CAUS}

As tentativas para se realizar um mapeamento consistente da arte urbana em Juazeiro tiveram início em 2015, com as primeiras fotografias capturadas. Nos outros anos, captamos também conteúdo em vídeo no espaço urbano desse município, no intuito de anexá-los à plataforma usada para desenvolvimento do CAUS e do SmartChico. Além de varrer a web em busca de indícios atrelados com a arte urbana na região, jornadas contemplativas foram realizadas como uma espécie de "caça ao tesouro", que descobrisse intervenções nos espaços públicos.

Junto a essas capturas fotográficas, foi iniciado um trabalho de prototipação do aplicativo, utilizando serviços de busca e visualização do OpenStreetMap $p^{6}$, base de informações georeferenciadas mantida por uma comunidade mundial de mapeadores voluntários. Todos os dados armazenados são abertos (Open Database Licence) e permite a distribuição sob a mesma licença. Para implementar a interface, usamos também a biblioteca JavaScript ${ }^{7}$ da Leaflet ${ }^{8}$. Trata-se de um serviço de código aberto, apropriado para mapas interativos e compatível com dispositivos móveis.

Para uma melhor organização das tarefas desempenhadas, dos estudos e a divulgação simultânea das

6. Disponível em: <https://www.openstreetmap.org/>. Acesso em: 21 fev. 2014. 7. Linguagem de programação executada no interior de softwares, de outras linguagens ou em outros ambientes. Servem para estender funcionalidades e controles através do acesso de $A P I$.

8. Disponivel em: <http://leafletjs.com/>. Acesso em: 21 fev. 2014 informações, foi elaborado um site ${ }^{9}$ que reúne, entre outras anotações, descrição sobre as propostas, agenda, memórias, roteiros, fichamentos, resenhas, mapeamentos, visualizações, vídeos e fotografias. 0 layout da página foi desenvolvido utilizando a plataforma semântica e os modelos de apresentação visual do WordPress.

A leitura do ambiente com o dispositivo de localização fornece as coordenadas geográficas (latitude e longitude) que, juntas às imagens das obras, preenchem os campos da interface web desenvolvida com o auxílio das ferramentas do OpenStreetMap e da biblioteca Leaflet. Como a interface foi toda desenvolvida com uma linguagem interativa, compatível com dispositivos móveis (web app), o próximo passo foi fazer com que ela interoperasse de maneira mais ampla, arquitetando, então, o aplicativo SmartChico. Com o app, além da capacidade de atividade isenta de conexão com a Internet (offline), novas operações podem ser somadas ao integrar as anotações e funcionalidades do dispositivo como contatos, geolocalizador, câmera, acelerômetro, bússola, etc.

A arquitetura do aplicativo foi desenvolvida para atender o público escolar dos ensinos fundamental, médio e superior, que interage com componentes curriculares relacionados ao campo das artes, mas não se restringe ao círculo da educação formal. Apresenta um padrão visual para ser intuitivo e adaptável, concentrando qualidades lúdicas que apontam para a localização, a descoberta, a criação e o compartilhamento de informações. Na interface principal, marcações sobre o mapa indicam a incidência da urbanografia sobre uma determinada coordenada. Ao clicar, a representação da obra é exibida em fotografia, ao tempo que é sugerido um trajeto, baseado na localização do usuário, para se alcançar o espaço físico do destino descoberto (FIG.1). É reservado também um campo com informações sobre as obras, biografias de artistas, notícias e outras publicações em torno do universo da arte urbana.

\footnotetext{
9. (http://caus.eco.br/)
} 
Figura 1- Mapeamento da urbanografia em Juazeiro-BA

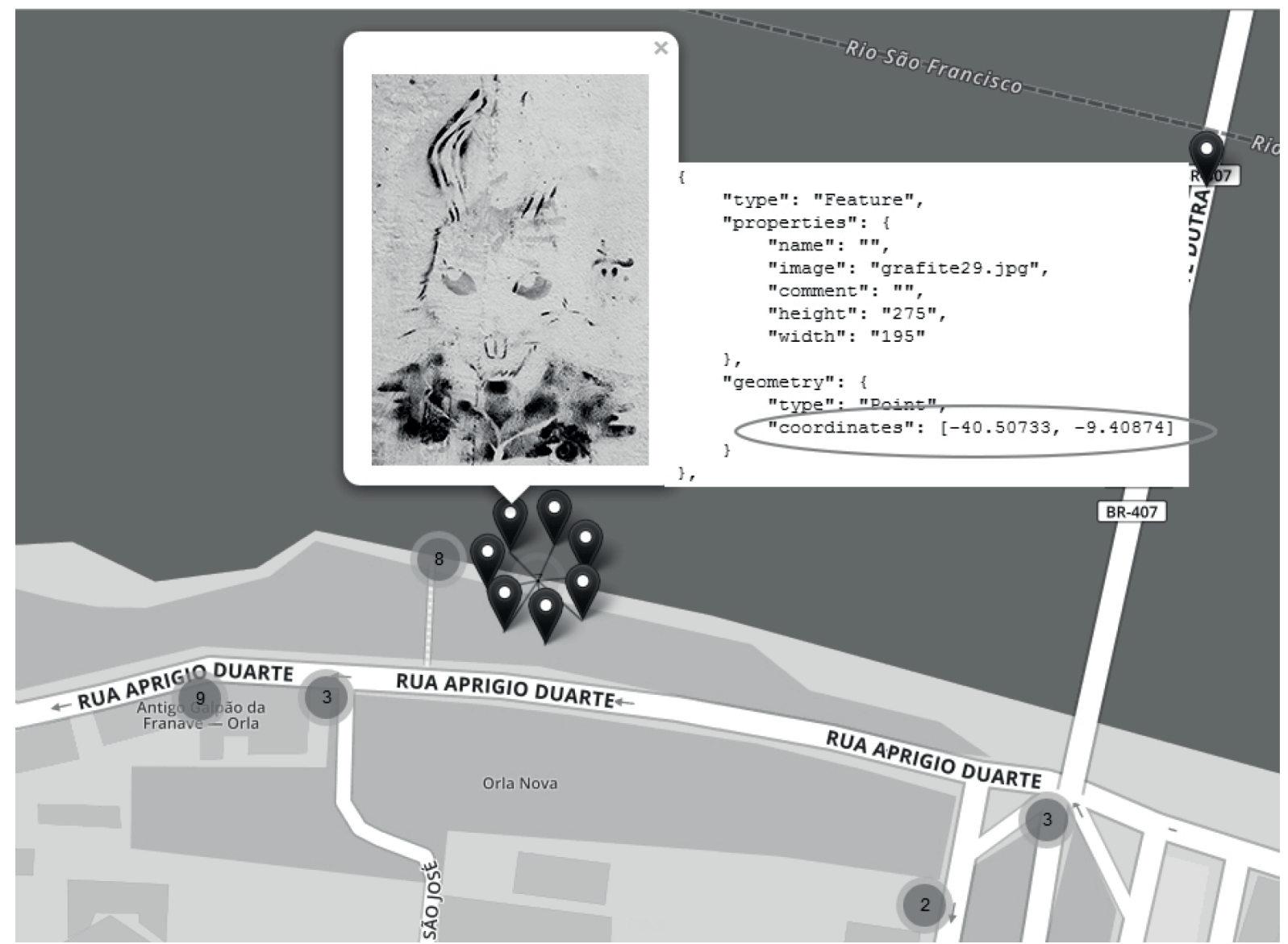

Fonte: CAUS, 2016. Interface indica a localização das obras no espaço urbano de Juazeiro a partir da posição do usuário. Disponível em: <https://goo. $\mathrm{gl} / \mathrm{z} \mathrm{YBr} 5 \mathrm{l}>$. Acesso em: 05mai. 2017.

\section{CONSIDERACÕ̃ES FINAIS}

Ao estabelecer conexões com um aplicativo, a urbanografia pode aumentar sua capacidade de interação e repasse de mensagens. As mídia locativas assessoram esse processo, tornando a expressão novamente sensitiva em seu estado físico inerte, passando a figurar como ator importante para conceber a urbanografia como um elemento com propriedades de reação às incitações. Uma intervenção artística na cidade pode expressar determinadas compreensões do espaço (a localização por coordenadas geográficas, por exemplo) ao executar comandos que processam dados adquiridos por sensores espalhados no ambiente.

A crescente potência das qualidades sensitivas da urbanografia, além de ser facilitada pelas mídias locativas, requer o compartilhamento irrestrito de dados. Esses, para uma clara leitura e continuidade de fluxo, necessitam transitar por sistemas interoperáveis capazes de concentrar bases e mantê-las em circulação. A urbanografia impregna e aciona nos espaços sub- 
jetividades suspensas, experiências que pulverizam e reforçam delimitações entre territórios, sejam analógicos, lógicos ou imaginários. A complexidade do sistema simbólico que ela impõe na paisagem conjetura aspectos que marcam a formação de lugares. As intervenções artísticas espalhadas nas vias da cidade de Juazeiro-BA não se resumem a substrato, adereço dos caminhos urbanos. São, sobretudo, expansões de significados, incorporações e relações estabelecidas na existência.

Na medida que as pigmentações ocupam os espaços como um prolongamento da sua própria materialidade, relações são intensificadas, exteriorizadas e interiorizadas em sequência. Isto gera uma experiência devedora da criação de um lugar, formado a partir da posição do usuário do SmartChico, o campo visual criado entre ele e a obra de arte, e o espaço urbano, que torna-se o suporte para esse processo. Sob este ponto de vista, o lugar passa a ser concebido como um mediador entre usuário, urbanografia e cidade. Este lugar é dotado de localização, local e sentido, que pode ser subjetivo e/ou compartilhado pela Internet com outros usuários. As leituras, codificações e decodificações aplicadas pelos envolvidos indiciam a coexistência de profundos discursos paralelos, atrelados a interesses mútuos e nem sempre fiel a percepção de uma dada realidade. As maneiras de deciframento que se revelam compreendem ações de instâncias que também são responsáveis por potencializar diferentes estabelecimentos e classes de vínculos.

É possível considerar, então, que a urbanografia estimula forças com outros elementos e processos, ao tempo que provoca interferências para a transformação de uma porção de espaço em um lugar dotado de sentido, a partir do uso consciente de um objeto - em nosso caso, o smartphone. Neste sentido, projetamos um objeto de aprendizagem (OA) que auxiliasse a produção de lugares sobre o espaço urbano, a partir da localização de peças da arte de rua. Consciente das atuais discussões sobre o uso, também o desuso, de objetos técnicos na sala de aula, optou-se por arquitetar um aplicativo competente para funcionar como elemento de adição nos trâmites associativos. A capa- cidade do aplicativo em agir junto com a urbanografia e o espaço urbano corresponde à arquitetura das competências do código, que problematiza as acepções da cultura e da arte regionais.

\section{REFERÊNCIAS}

ARAÚJO, James Amorim. Sobre a cidade e o urbano em Henri Lefebvre. GEOUSP: Espaço e Tempo, São Paulo, n. 31, p. 133-142, jun. 2012. Disponível em: <http:// citrus.uspnet.usp.br/geousp/ojs-2.2.4/index.php/ geousp/article/view/576>. Acesso em: 23 nov. 2015.

CARTAXO, Zalinda. Arte nos espaços públicos: a cidade como realidade. 0 Percevejo Online, Rio de Janeiro, v. 1, n. 1, p. 01-16, 2009. Disponível em: <http://www.seer.unirio.br/index.php/ opercevejoonline/article/view/431/380>. Acesso em: 17 jul. 2015.

CERTEAU, M. A invenção do cotidiano. Petrópolis: Vozes, 1994.

CRESSWELL, T. Place: a short introduction. London: Blackwell, 2004.

CRUZ, A; NERI, D. A inserção dos tablets em escolas da rede pública estadual na cidade de Petrolina PE: uma percepção dos educadores e educandos.

Revista de Educação do Vale do São Francisco (REVASF) vol.4, n.6. Petrolina: Univasf, 2014.

FREIRE, Paulo. Política e educação. São Paulo: Cortez, 1993.

FREIRE, Paulo.. Pedagogia do oprimido. São Paulo: Paz e Terra, 2009.

GADOTTI, Moacir. A escola na cidade que educa. Cadernos Cenpec, [S.l.], v. 1, n. 1, maio 2006. Disponível em: <http://cadernos.cenpec.org.br/ 
cadernos/index.php/cadernos/article/view/160>. Acesso em: 12 nov. 2016.

LEFEBVRE, Henri. La production de l'espace. 4. ed. Paris: Anthropos, 2000.

\section{LEFEBVRE, Henri. 0 direito à cidade. Rubens \\ Eduardo Frias (Trad.). São Paulo: Centauro, 2001.}

\section{LEFEBVRE, Henri. A Revolução urbana. Belo}

Horizonte: EdufMG, 2004.

LEMOS, A. Você está aqui! mídia locativa e teorias da "materialidades da comunicação" e "ator-rede".

Comunicação e Sociedade, São Paulo, Ano 32, n. 54, p. 5-29, 2010.

\section{MEDEIROS, M. 0 lugar da comunicação: um estudo sobre a comunicação locativa em zonas bluetooth.} 2011. 313 f. Tese (Doutorado) - Faculdade de Comunicação, Universidade Federal da Bahia. Salvador, 2011.

MENDES, Eloísa Brantes. Cidades instáveis: intervenção artística como experiência heterotópica do espaço urbano. 0 Percevejo Online, Rio de Janeiro, v. 4, n. 2, p. 01-19, ago./dez. 2012. Disponível em: <http://www.seer.unirio.br/index. php/opercevejoonline/article/viewFile/2923/ pdf_736>. Acesso em: 11 jun. 2015.

\section{PALLAMIN, Vera Maria. Arte Urbana; São Paulo:}

Região Central (1945-1998): obras de caráter temporário e permanente. São Paulo: Fapesp, 2000. Disponível em: <http://www.fau.usp.br/fau/ensino/ docentes/deptecnologia/v_pallamin/arte_urbana_ livro.pdf>. Acesso em: 11 jul. 2015.

PEREIRA, Vanderléa Andrade. O lugar da arte no espaço cotidiano da convivência com o Semi-árido. In: RESAB, Secretaria Executiva. Educação para a convivência com o Semiárido: reflexões teóricopráticas. 2. ed. Juazeiro: Resab, 2006. p. 185-193.

TUAN, Yi-Fu. Espaço e lugar: a perspectiva da experiência. Livia de Oliveira (Trad.). Londrina: Eduel, 2013. 